\title{
Formation of a true knot in subclavian venous catheter in a patient in the intensive care unit
}

\author{
Dmytro A. Shkurupii ${ }^{1} \bowtie$, Dmytro A. Kholod ${ }^{2} \bowtie$ \\ Author affiliations: \\ 1- Chairman of Separate Division of the Association of Anesthesiologists of Ukraine in the Poltava region, Chairman of \\ Department of Anesthesiology \& Intensive Care, Ukrainian Medical Stomatological Academy, Poltava (Ukraine); ORCID \\ number: 0000-0003-3803-4444 \\ 2- Department of Anesthesiology and Intensive Care, Ukrainian Medical Stomatological Academy; Shevchenko str. 23, \\ Poltava, Ukraine, 36011. ORCID number: 0000-0001
}

Correspondence: Dmytro A. Shkurupii, Separate Division of the Association of Anesthesiologists of Ukraine in the Poltava region; Shevchenko str. 115-30, Poltava, Ukraine, 36039. Tel.: +38(066)236-96-70. E-mail: d.a.shkurupiy@gmail.com

\section{Abstract}

Vascular catheters are most frequently used in the critical care units. A true knot in the catheter is a rare mechanical complication of the central venous catheterization. A 14-year-old patient was treated for acute appendicitis complicated by diffuse peritonitis. It was decided to insert a central venous catheter on the first day of treatment. A catheter was inserted in the right subclavian vein according to Seldinger technique. It functioned perfectly for 6 days. On 7th day, during its removal, its extraction was blocked at about $1 \mathrm{~cm}$ depth from the tip. The catheter had to be removed forcefully with the formation of a hematoma at the entry point of the catheter. Once removed, we found a true knot formed tightly inside the vessel. In this case, no disabling and life-threatening complication was recorded, and the patient was discharged when fully recovered.

Key words: Catheterization; Clinical event; Complications; Knot; Subclavian vein

Citation: Shkurupii DA, Kholod DA. Formation of a true knot in subclavian venous catheter in a patient in the intensive care unit. Anaesth. pain intensive care 2020;24(6):664-666; DOI: 10.35975/apic.v24i6.1372

Received: 18 October 2020, Reviewed: 27 October 2020, Accepted: 31 October 2020

\section{1- Introduction}

Among other manipulations, intravascular catheter insertion is the most frequently practiced procedure in critical care units. In the United States of America, the total duration of the use of the great vessel catheters is about 15 million days per year. ${ }^{1}$ Insertion of the catheter in a great vessel is an interventional manipulation and has been associated with a number of complications reaching 29\% according to one study. ${ }^{2}$ Among these, infections and thrombotic complications occur with the highest frequency. ${ }^{3}$ The formation of the catheter knot in the vessel lumen is a serious, but pretty rare mechanical complication of the central venous catheterization with a frequency of
$0.1 \%$ of all catheterization complications. ${ }^{4} \mathrm{We}$ document one such case, just to apprise the intensive care specialists and the anesthesiologists that this complication can occur and must be looked for in difficult catheter extraction.

\section{2- Case Report}

A 14-year-old patient of a Caucasian race, weighing about $58 \mathrm{~kg}$ was treated in the department of anesthesiology and intensive care for acute appendicitis complicated by diffuse purulent peritonitis. In addition to the surgery, the treatment included antibiotic therapy, infusion therapy, parenteral feeding, metabolic therapy, and analgesics. Considering the requirement of infusion of large 
volumes of hyperosmolar solutions, necessity of complete parenteral feeding and continuous monitoring of the hemodynamic parameters, we decided to install the central venous catheter on the very first day of treatment.

The right subclavian vein catheterization was carried out under Seldinger technique after disinfection of the surgical area, and under aseptic conditions, by a blind method accessing from the Aubaniac point via the infraclavicular approach. The vein was needled in the first attempt; a polyvinylchloride sheath was freely introduced over the needle to the depth of $6 \mathrm{~cm}$. The dilator was not used. The polyvinylchloride $19 \mathrm{G}$ catheter was introduced to the same depth. Blood flow in the catheter was free in both directions. The catheter was fixed to the skin by a silk stitch. Aseptic dressing was applied.
The catheter functioned properly for 6 days for infusions and frequent blood sampling for laboratory investigations without any difficulty. On the $7^{\text {th }}$ day, we noticed that there was a reduction in the flow of the intravenous infusion. So it was decided to remove the catheter. In the process of removal of the catheter, its extraction was blocked at about $1 \mathrm{~cm}$ depth from the tip. The attempts to remove the catheter by moving to and fro, and introducing the sheath into the catheter failed. There was no opportunity to use visualizing techniques to assess the location of the catheter in the vessel at the moment of manipulation and the doctor pulled and removed the catheter forcefully. The catheter was removed without serious clinical consequences. After removal of the catheter, $1 \mathrm{~cm}$ apart from its tip we found a true knot, which formed inside the vessel (Figure 1).

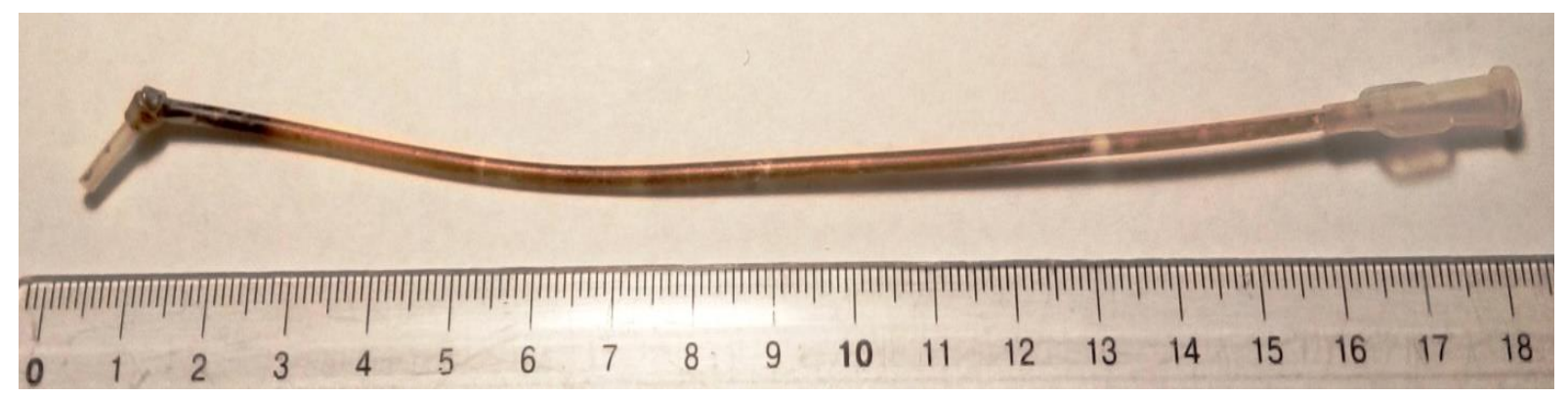

Figure 1: The catheter with a formed knot after removal from the vessel

In this case, no disabling and life-threatening complication as a result of the use of the catheter was recorded. The patient was discharged when fully recovered.

\section{3- Discussion}

The use of radiological means of visualization increases the success rate of catheterization of great vessels and decreases the number of associated complications. ${ }^{5}$ In the particular case described here, these methods were not used and insertion of the catheter was successfully accomplished. Thus, it was impossible to identify the depth during insertion of the catheter and the formation of a knot, which was only noticed after removing the catheter.

It is suggested that too deep introduction of the catheter caused its abnormal bending inside the vessel when reached a mechanical obstacle. These obstacles may include: vessel wall, anatomical angle between subclavian and jugular veins, as well as multiple vessel valves specific for the subclavian vein. ${ }^{6}$ Proper functioning of the catheter inside the vein for so many days shows that formation of the knot may have occurred at the moment of insertion but it remained loose and did not occlude the catheter completely.

A hematoma that formed as a result of the physical forceful removal of the catheter means that such a manipulation is invariably traumatic in terms of the vessel wall. In our case, this trauma didn't have a gross negative effect on the patient. This case report is in agreement to other authors ${ }^{7}$ and affirms the necessity of using visualization techniques during manipulations associated with the great vessels catheterization.

It is noteworthy that in this particular case, we used the polyvinylchloride catheter being thicker and less flexible compared to the catheters. ${ }^{89}$ It suggests that this particular case of formation of a true knot is rather rare than a regular one.

\section{4- Conclusion}


Radiological guidance and visualization of the location of the venous or arterial catheters in the vessels should be used, while inserting or removing the catheters. If such facilities are not available, the depth of the catheter introduced into a vessel should be precisely calculated. The catheter knot may serve as a possible mechanical obstruction, if it is hard to remove the catheter from the great vessel. Forceful removal of the catheter, having an intravascular knot, is dangerous in terms of vessel wall traumatization.

\section{5- Disclaimers}

Views expressed in the submitted article are author's views and not an official position of the institution

\section{6- Conflict of interest}

No conflict of interest declared by the authors

\section{7- Authors' contribution}

DAS: idea and description of the clinical case.

DAK: literature search, text writing.

\section{8- References}

1. O'Grady NP, Alexander M, Burns LA, Dellinger EP, Garland J, Heard SO, Lipsett PA, Masur H, Mermel LA, Pearson ML, Raad II, Randolph AG, Rupp ME, Saint S; Healthcare Infection Control Practices Advisory Committee (HICPAC). Guidelines for the prevention of intravascular catheter-related infections. Clin Infect Dis. 2011 May;52(9):e162-93. [PubMed] [Free Full Text] DOI: $10.1093 / \mathrm{cid} / \mathrm{cir} 257$.

2. Erkılıç Erkılıç E, Aksoy M, Gümüş T, Sarı S, Kesimci E. Jugular Venous Catheterization: A Case of Knotting. Case Rep Med. 2015;2015:810346. [PubMed] [Free Full Text] DOI: $10.1155 / 2015 / 810346$.

3. Machat S, Eisenhuber E, Pfarl G, Stübler J, Koelblinger C, Zacherl J, Schima W. Complications of central venous port systems: a pictorial review. Insights Imaging. 2019 Aug 28;10(1):86. [PubMed] [Free Full Text] DOI: $10.1186 / \mathrm{s} 13244-019-0770-2$.

4. Oshima M, Onishi T, Iwata H, Aoyama K. Identical wave forms of vena cava and pulmonary artery during pulmonary artery catheter insertion due to kinking: a case report of a rare complication. Springerplus. 2016 Aug 19;5(1):1367. [PubMed] [Free Full Text] DOI: 10.1186/s40064-016-3050-3

5. Rezayat T, Stowell JR, Kendall JL, Turner E, Fox JC, Barjaktarevic I. Ultrasound-Guided Cannulation: Time to Bring Subclavian Central Lines Back. West J Emerg Med. 2016 Mar;17(2):216-21. [PubMed] [Free Full Text] DOI: $\underline{10.5811 / \text { westjem.2016.1.29462 }}$

6. Kalińczuk Ł, Chmielak Z, Dębski A, Kępka C, Rudziński $\mathrm{PN}$, Bujak $\mathrm{S}$, et al. Percutaneous retrieval of centrally embolized fragments of central venous access devices or knotted Swan-Ganz catheters. Clinical report of 14 retrievals with detailed angiographic analysis and review of procedural aspects. Postepy Kardiol Interwencyjnej. 2016;12(2):140-55. [PubMed] [Free Full Text] DOI: 10.5114/aic.2016.59365.

7. Santos FKY, Flumignan RLG, Areias LL, Sarpe AKP, Amaral FCF, Ávila RB, Vasconcelos VT, Guedes Neto HJ, Amorim JE, Nakano LCU. Peripherally inserted central catheter versus central venous catheter for intravenous access: A protocol for systematic review and meta-analysis. Medicine (Baltimore). $2020 \mathrm{Jul}$ 24;99(30):e20352. [PubMed] [Free Full Text] DOI: 10.1097/MD.0000000000020352.

8. Karian HG, editor. Handbook of Polypropylene and Polypropylene Composites. New York: MarcelDekker Inc; 2003.740. Available at: https://dokumen.pub/qdownload/handbook-ofpolypropylene-and-polypropylene-composites2nbsped-9780824740641-0-8247-4064-5.html

9. A Guide To Glycols. The Dow Chemical Company. 2003. 44. [Free Full Text] 